\title{
Apresentação / Presentation
}

\section{Vida na rua \\ Contribuições analíticas do campo das Ciências Sociais}

\author{
Life on the street
}

Analytical contributions from the field of Social Sciences

\section{Cristina Almeida Cunha Filgueiras ${ }^{1}$ \\ (1) Regina de Paula Medeiros ${ }^{1}$ \\ (1) Pascale Pichon ${ }^{2}$ \\ Gabriel Uribelarrea ${ }^{2}$}

presença de pessoas vivendo nas ruas das cidades é uma realidade antiga
le persistente. Trata-se de um fenômeno complexo, que ocorre em países com diferentes graus de desenvolvimento, que implica falta de alternativas socioeconômicas ou na escolha individual de morar sem endereço e com o mínimo de recursos para sobrevivência. As causas estruturais do fenômeno nos países desenvolvidos são hoje bem conhecidas: falta de acesso a direitos, precarização do emprego, redefinição das políticas públicas de proteção e assistência. Com frequência, essas condições estão associadas ao rompimento de laços familiares, sociais e de trabalho e com as normas sociais. Pessoas, sozinhas ou em companhia de outras, que fazem do espaço público o seu lugar de vida, que expõem seus corpos e pertences em ruas, praças ou viadutos, provocam diversos tipos de reações sociais, políticas e institucionais.

Embora seja um fenômeno recorrente ao longo da história, tem diferentes formas de denominação ou de foco. Não existe em português um neologismo semelhante aos termos homelessness (Levinson, 2004), em inglês, e sansabrisme (Chopin, Gardella 2013), em francês, criados para designar este fenômeno. A proposta deste dossiê é reunir trabalhos sobre esta realidade humana, social e urbana como "vida na rua". Ela tem sido objeto de análise acadêmica e estudos em variadas áreas do conhecimento científico, com suas especificidades. Nas Ciências Sociais é vasta a produção analítica sobre o tema, existem centros de pesquisas e redes internacionais de especialistas dedicados

\footnotetext{
${ }^{1}$ Pontifícia Universidade Católica de Minas Gerais (Pucminas, Belo Horizonte, MG, Brasil).

${ }^{2}$ Université de Lyon/Jean Monnet, Centre Max Weber (Sainte-Étienne, France). autores.dados_biográficos
} 
a estudá-lo. Os focos de estudos são muito diversificados, alguns põem ênfase em explicações do fenômeno, mobilizando os aspectos estruturais, processuais e sócio-históricos; outros com abordagens compreensiva e interacionista dão ênfase à experiência das pessoas que vivem nessa condição e às reações sociais à essa forma de vida. O certo é que a "vida na rua" mobiliza pesquisadores do campo das Ciências Sociais, estimula as abordagens micro e macrossociológica, análises que interroguem sobre o indivíduo e o social, as tensões entre estrutura e agência, entre representações e materialidade.

São muitas também as escalas de análise, do microterritório em uma cidade à visão global/migração internacional, conforme exemplificam os textos aqui publicados. O dossiê traz doze artigos, os quais abordam a vida na rua em cidades específicas ou não. Nele são estudadas situações em quatro países: Colômbia, México, Portugal e Brasil. São oito as cidades: Tijuana, Bogotá, Porto, Belo Horizonte, Cuiabá, Fortaleza, São Paulo e Porto Alegre. Ao analisar o fenômeno em uma determinada cidade, os pesquisadores aportam particularidades, porém abordam realidades que se repetem, expressões locais de um fenômeno social e urbano que ocorre em quase todo o mundo. Em uma visão do conjunto, observamos pontos em comum e especificidades locais.

O conjunto de artigos que compõe esse dossiê inclui diálogos com as obras de autores da literatura internacional do campo das Ciências Sociais. Além disso, é possível fazer múltiplas aproximações dos artigos com trabalhos sobre o tema na Europa, nos Estados Unidos e no Brasil. Para citar alguns, as investigações e publicações de Pascale Pichon (2005; 2007), Pichon e Torche (2007) e Pichon, Girola e Jouve (2016), os trabalhos de Michel Agier (2010) sobre os acampamentos na Europa e várias outras situações ao redor do mundo, as análises de David Snow (1998) sobre o povo da rua e de Philippe Bourgois (2015) sobre territórios marginais, os estudos realizados nos Estados Unidos (Hopper, 2002) e Canadá (Laberg, 2000; Roy et Hurtubise, 2007) e, no Brasil, uma variedade de contribuições que, na impossibilidade de citar todas aqui, poderiam ser exemplificadas pela coletânea organizada por Rui, Martinez e Feltran (2016) e o trabalho de Frangella (2010).

As escalas e enfoques podem ir, por exemplo, da migração internacional à deambulação de uma pessoa pelas ruas de uma cidade determinada, ou do fenômeno social à experiência individual. Se o foco é a experiência, em geral os pesquisadores encontram, interagem e dialogam com os atores sociais. Cada pessoa possui uma história biográfica singular e, ao mesmo tempo, atravessa situações parecidas às das demais, situações típicas da condição de viver na rua que constituem finalmente as etapas da "carreira de sobrevivência" (Filgueiras e Pichon, 2017). 
A visão do conjunto permite perceber ainda populações, categorias (os que ficam na rua, os que estão na rua, os que são da rua), hierarquias sociais, poderes, instituições e territórios. As pessoas que vivem na rua não apenas ocupam espaços urbanos, elas organizam e produzem com seu modo de vida os espaços públicos, subvertem a ordem urbana com seus corpos e pertences que investem de forma efêmera certos lugares.

Nos artigos são mencionadas e examinadas diversas fronteiras associadas à vida na rua: fronteiras sociais, divisa entre territórios intraurbanos sejam esses geográficos ou simbólicos; fronteiras entre gerações; entre países, onde deportados se tornam moradores de rua; limite entre territórios de droga e outros espaços urbanos; fronteiras-linhas de demarcação entre diferentes tipos de vida na rua; limiar entre militantes e apoiadores do movimento social. Além disso, há fronteiras estabelecidas pelas categorizações, tipologias utilizadas por órgãos públicos ou por pesquisadores ao identificar características especificas entre as pessoas que moram nas ruas.

Consideramos indispensável nesta apresentação chamar a atenção dos leitores para os aspectos epistemológicos, metodológicos e éticos da pesquisa sobre a vida na rua. Nota-se nos artigos que virão a seguir, menções ao uso de ampla gama de recursos de investigação. Fazendo um rápido apanhado das abordagens, procedimentos e técnicas que os autores mencionaram nos artigos, encontramos majoritariamente estudos qualitativos, sendo uma parte significativa deles de caráter etnográfico. As etnografias são de diversas modalidades, conduzidas de diversas maneiras: participativa (colaborativa), conduzidas por um único pesquisador ou por um grupo; incluindo ou não os espaços institucionais de acolhida dos moradores de rua. Em um dos textos, os autores relatam a revisita ao campo etnográfico analisado vinte anos antes. São apontados no dossiê o uso de entrevistas, de diversos tipos de relatos orais, narrativas biográficas, descrição de usos e práticas cotidianas. Está presente ainda o recurso a dados de fontes governamentais: planos e outros documentos; estatísticas administrativas e levantamentos censitários. A pesquisa documental, central para a análise genealógica, foi um dos recursos empregados por uma das autoras. A investigação de corte amostral com uso de questionário foi assinalada em um dos artigos, e faz parte de um trabalho amplo que combina este recurso com estudo qualitativo. Outro procedimento, destacado em um dos textos do volume, é a revisão ampla das investigações, que brinda o estado da arte em um período determinado, está presente no artigo sobre crianças e adolescentes na rua.

O dossiê entra no tema vida na rua colocando no centro da reflexão as pessoas - a que vive na rua e o pesquisador que busca compreender ou 
explicar aspectos dessa condição e vivência social e urbana. A rua é um lugar de vivência e experiência, por essa razão é um lugar privilegiado de pesquisa.

Pensar a rua como uma experiência de vida para as pessoas que nela vivem (e não só ocupam o espaço urbano) é justamente o foco do primeiro artigo. Nele as pesquisadoras colombianas Nataly Camacho Mariño e Carolina Rodríguez Lizarralde, respectivamente, antropóloga e cientista política, buscam responder à pergunta "O que é a rua?". Em suas palavras, a rua é plural, complexa, polifônica, multitemporal e multisituada, uma rede de lugares, é espaço vivido e não apenas de trânsito. As autoras problematizam a experiência das pessoas que vivenciam o que denominam a "rua-rua", isto é, a situação de não ter um domicílio fixo e experimentar um grau elevado de exposição e precariedade, o limite de subsistência física e material. $\mathrm{O}$ cotidiano de Lesly, uma jovem de 21 anos nos territórios de droga de Bogotá, mostra que viver a "rua-rua" requer aprender códigos, valores, normas, estratégias e, sobretudo, que "nada é gratuito". As autoras examinam ainda os espaços institucionais de acolhida, e, neles, as relações de poder, assim como a produção de discursos e práticas pelos que vivem na rua. Além disso, o texto inclui necessária reflexão sobre a experiência como mulheres pesquisadoras que estudam a rua, o que significa inclusive arriscar-se em lugares socialmente percebidos como inseguros e perigosos.

A territorialização praticada pelo morador de rua, o viver $n a$ rua e o viver $d a$ rua, o produzir a rua como lugar existencial e simbólico são examinados no artigo de Jorge Garcia de Holanda que apresenta Roberto, de 55 anos de idade, da cidade brasileira de Fortaleza. Ao conhecer as experiências de Roberto, o leitor é levado a conhecer os modos de sustento na rua, a permanência em um local e a mobilidade (andar muito, percorrer longas distâncias), o mangueio, a insegurança, a violência entre os moradores de rua. $\mathrm{O}$ autor distingue o sistema da rua do se virar na rua. O primeiro diz respeito aos fatores estruturais que impelem as experiências negativas de viver na rua (processos de exclusão e violência), que são recorrentes a indivíduos que estão nessa situação: privação, adversidades, dificuldades nos períodos de chuva, disputas, abusos policiais, em síntese, a submissão ao modo de organização da vida próprio da rua, "por si mesma, limitadora, cruel e de grande exigência emocional e física". A segunda categoria, se virar na rua, está associada principalmente às dimensões de agência, à ação e à inventividade do indivíduo: adaptação, aprendizagem de habilidades e conhecimentos práticos para se manter na rua e produzir-se como sujeito.

Os moradores de rua são com frequência vistos como perigosos, porém também podem ser úteis para a gestão urbana no neoliberalismo no qual a cidade foi transformada em commodity e os projetos de requalificação se sucedem, 
conforme mostra Karine Gonçalves Carneiro em seu artigo. Combinando a abordagem genealógica de Michel Foucault - o poder disciplinar sobre o indivíduo e o biopoder sobre as populações - a autora analisa a produção do espaço e o modo de vida dos moradores de rua em duas metrópoles sul americanas. Nessas metrópoles o hipercentro é zona privilegiada tanto para investimentos públicos e privados (neles a terra urbana possui alto valor econômico) quanto para a presença de moradores de rua (ali estão muitos dos recursos para a sobrevivência de quem vive na rua). A autora se interessa pelos impactos e desdobramentos sobre o modo de vida dos moradores de rua provocados pela lógica da nova governabilidade que se expressa no empreendedorismo urbano, nos projetos de requalificação urbana, em planos de ordenamento territorial e na especulação com o valor da terra. Nesse contexto, os moradores de rua são frequentemente apontados como responsáveis pela sujeira, mau uso, desordem urbana, usos de drogas, insegurança e perigo. Sua presença está associada à desvalorização dos terrenos e tem sido usada para justificar o discurso favorável às intervenções urbanas, para embasar os megaprojetos de renovação urbana e "fazer renascer o centro". Se seguirmos a argumentação da autora, fica claro que as pessoas que vivem na rua não estão à margem das dinâmicas centrais da sociedade contemporânea, ao contrário, estão de forma perversa conectadas aos principais processos econômicos e de poder.

$\mathrm{O}$ fato de os moradores de rua serem parte das estruturas sociais de classe e de poder na sociedade contemporânea é base da análise realizada por Carolina Nakagawa Lanfranchi e Viviane Canecchio Ferreirinho. As autoras adotam no seu artigo a perspectiva bourdieusiana e investigam a rua como um campo social com seus sistema de posições e disposições próprias e onde o habitus é formado, assim como é adquirido e manejado um determinado tipo de capital (isto é, o que é valioso entre as pessoas do campo, neste caso, as fontes de aquisição de alimentos, de trabalho, conhecimento da rede, espaços na cidade, etc.). Dessa forma, buscam superar a perspectiva que individualiza o morador de rua, para entendê-los como parte da estrutura de poder. Examinam no texto, a condição de pessoas que vivem na rua na cidade de São Paulo, a partir de dados da administração municipal que lhes permitiram "delimitar a população em situação de rua com o espaço social dotado de regras e posições sociais", identificar disposições e as classificações produzidas. A análise apresentada leva à uma hierarquia formada por quatro grupos de status e sistemas de posições classificáveis dentro do campo (rua): lideranças, acolhidos com alto grau de institucionalização, grupos ou indivíduos que alternam pernoite nas ruas e acolhimento nos serviços, e indivíduos isolados com forte resistência à institucionalização. 
O texto de Melissa de Mattos Pimenta traça o perfil sociodemográfico da população adulta em situação de rua na cidade de Porto Alegre e examina o relacionamento desta população com as instituições de atendimento e, ainda, a sua percepção sobre como é tratada pelos demais residentes da cidade. No artigo são discutidos resultados de uma contagem da população em situação de rua e de uma pesquisa quali-quanti, realizada por pesquisadores da Universidade Federal do Rio Grande do Sul, em cooperação com o órgão gestor da política de assistência social; usa a metodologia participativa que envolveu pesquisadores, bolsistas, usuários dos serviços especializados e integrantes do Movimento Nacional de População de Rua e do jornal Boca de Rua. A presença deste artigo no dossiê contribui para destacar que estatísticas são importantes para dar a dimensão do problema (para a cidade pesquisada e em um momento determinado) e são necessárias para pensar sobre grande variedade de aspectos, contribuição que se amplia quando combinada com estudos qualitativos. Além disso, o artigo chama a atenção para a variedade de atores que podem estar envolvidos, juntamente com os pesquisadores acadêmicos, na produção de informação e conhecimentos sobre a vida na rua.

As múltiplas dimensões do persistente problema de crianças e adolescentes vivendo nas ruas no Brasil constituem objeto da análise realizada por Irene Rizzini e Renata Mena Brasil do Couto em artigo que apresenta uma revisão das investigações realizadas no país entre 2000 e 2015. As autoras se debruçaram sobre uma base de 116 artigos, teses e dissertações, retiradas de um levantamento de mais de 800 títulos. $O$ balanço feito por elas contribui para indicar avanços nas investigações sobre esta realidade e distinguiu os seguintes temas mais frequentes nos trabalhos consultados: perfil de quem vive na rua; família; violência; trabalho; instituições de acolhida; consumo de droga; educação/escola; e saúde. Segundo as autoras, o material consultado traz evidências do avanço na adoção de normativas que visam garantir os direitos desse segmento da população e, ademais, permitiu identificar recomendações que visam contribuir para ampliar e aperfeiçoar as políticas públicas dirigidas às crianças e adolescentes em situação de rua.

A dimensão coletiva e associativa da vida na rua é tratada por Tiago Lemões em artigo sobre a militância política no Movimento Nacional de Moradores de Rua. A contribuição do autor é fundamental no conjunto deste dossiê por referir-se aos temas de organização, movimento social, e a construção no Brasil de estatuto político do morador de rua. Lemões menciona o brutal assassinato de um grupo de pessoas que viviam na rua, ocorrido em 2004 na Praça da Sé, no coração de São Paulo, e a conexão desse trágico acontecimento com o surgimento do movimento social. Em seguida, examina 
criticamente as ações de formação política dos membros do movimento e as cartilhas de divulgação de direitos. São revisados o engajamento no MNPR, o papel dos representantes, as estratégias de recrutamento e mobilização (reuniões itinerantes, grupos de teatro de rua, distribuição de folhetos explicativos). Nesse processo o aprendizado é destacado pois, na visão dos militantes, para falar "não basta ser da rua", é preciso saber o que, quando e como falar, visando defender o que o movimento considera serem direitos. Outros, ao contrário, afirmam que "não se precisa de muito argumento para dizer que queremos comer". O artigo é uma contribuição importante sobre a politização das pessoas em situação de rua e sobre as instâncias responsáveis pela "gestão de visibilidades".

Os quatro artigos seguintes do dossiê abordam um tema incontornável na vida nas ruas e que já está presente no artigo que abriu este volume: as drogas. No primeiro deles, Regina de Paula Medeiros escreve sobre a organização dos moradores de rua para uso de drogas em determinados territórios no centro de Belo Horizonte. A autora chama a atenção que as cracolândias são regiões morais, pois “delimitar os espaços urbanos é uma estratégia classificatória de apartar, demarcar e cronificar os espaços da cidade com base em questões morais, sociais e política" que acabam por incidir sobre pessoas que fazem uso dele. Ao fazer a cartografia desses territórios, a pesquisadora mostra que, em Belo Horizonte, eles são pulverizados e fluidos, as fronteiras não são fixas. $\mathrm{O}$ trabalho etnográfico apresentado foi realizado com caminhadas a pé, durante o dia, com os moradores da região central da cidade, "com intuito de perceber a lógica dos circuitos feitos, rotinas, os espaços, representações simbólicas e as interações sociais". Dois pontos urbanos - a praça da Estação e o viaduto das Bolas - foram identificados como pontos de travessia (lugares de parada ou descanso), além de ser um espaço de sociabilidade e de interação social, é onde usam droga, levando ao exame do funcionamento desses locais e das regras de uso.

Em seu artigo Juan Antonio del Monte Madrigal discute a relação entre migração, deportação, consumo de drogas, o mercado de drogas, violência entre as pessoas que, após serem deportadas pelo governo dos Estados Unidos (em razão da política de criminalização dos migrantes não-documentados nesse país) vivem nas ruas na cidade fronteiriça de Tijuana no México. O autor alerta para o fato que a vida na rua nesse contexto obedece a particularidades que a distanciam do que em geral se analisa sobre os centros metropolitanos. Ou seja, a vida na rua não ocorre da mesma forma em todas as cidades, ao contrário, incidem sobre ela as características geográficas e as determinações históricas. O texto traz elementos de uma pesquisa realizada com foco biográfico, 
interessada em examinar os processos de precarização acumulativos e progressivos e em identificar possibilidade de agência de pessoas imobilizadas no espaço de fronteira. $\mathrm{O}$ desgaste nas condições sociais, legais, econômicas, a ausência ou esgarçamento de redes familiares e sócio afetivas, a imersão em mundos criminais, bem como a inexistência de programas governamentais de reinserção social para os migrantes deportados contribuem para a sua chegada e permanência nas ruas.

A territorialidade da venda e consumo de crack e outras drogas ilegalizadas foram pesquisados por Yamila Abal e Silvia Gugelmin. As autoras utilizam a noção de "populações ocultadas" para expor a tensão entre invisibilização e hipervisibilização dos moradores de rua nesse contexto. Analisam diversas cenas abertas no espaço público na cidade de Cuiabá, dentre elas a demolição na área da Ilha da Banana, local denominado pela mídia local como cracolândia cuiabana. A demolição foi justificada pelo poder público como parte do projeto de revitalização do centro histórico da cidade. As autoras destacam a espetacularização da "limpeza", realizada sob os holofotes da mídia, que resultou na dispersão dos grupos que habitavam a área. Uma vez mais, neste dossiê, são mencionados a repressão e o remanejamento de grupos rotulados como perigosos, com o objetivo de promover a valorização imobiliária de uma região do centro urbano que se tornara território onde há corpos desviantes, perigosos e matáveis. A etnografia realizada pelas autoras permitiu ver as cenas abertas de consumo de droga, de violência, sofrimento, contudo também possibilitou uma aproximação às relações de cuidado, estratégias de sobrevivência, as relações construídas no território como modos de existir e resistir.

Há territórios que são apresentados na mídia e identificados na representação social dominante como lugares do "mundo da droga". São por exemplo as ollas em Bogotá, ou as cracolândias nas cidades brasileiras, localizadas geralmente nas regiões centrais ou hipercentro urbano. Porém, o artigo de autoria de Simão Mata e Luís Fernandes se distingue dos anteriores por apresentar investigações realizadas em territórios psicotrópicos em bairros "de habitação social na periferia urbana". Eles revisitaram em 2014 os territórios psicotrópicos na cidade do Porto em Portugal onde haviam realizado etnografia no início dos anos 90 . No texto, observam a fluidez das fronteiras, territórios que se organizam em pleno espaço público, ainda que em zonas pouco frequentadas pelo cidadão comum, mas facilmente reconhecidas pelas atividades em torno de "capeadores" e "agarrados". Alguns desses espaços são mais públicos e claramente visíveis para quem se aproxima, outros são mais discretos, em dobras espaciais que resguardam dos olhares. Neste contexto, 
estabelece-se uma “distância que é menos física do que simbólica, entre os atores ligados às drogas e aqueles que em nada se relacionam com as atividades ditas desviantes", porém todos recebem as referências negativas atribuídas por pertencerem ao bairro das drogas.

O dossiê termina com o texto de caráter heurístico, de João Aldeia, que prontamente expõe a seguinte posição metodológica: "a vida na rua é menos interessante como objeto de estudo fechado sobre si mesmo do que como meio para aceder ao mundo em que existe". O autor toma a posição de que a vida na rua permite compreender diversos fenômenos da sociedade contemporânea. Ele adota, pois, perspectiva semelhante à do sociólogo Georg Simmel na sua conhecida análise sobre a pobreza como um fenômeno de síntese sociológica. Tal como Simmel propôs uma sociologia através da pobreza, João Aldeia propõe no artigo uma sociologia através da vida na rua (essa claramente uma manifestação dramática daquela). Ganham assim relevância as reações sociais, a alteridade, a interação de saberes, dominação e poder. $\mathrm{O}$ autor ressalta o caráter multiparadigmático da vida na rua, que ele expõe no texto com a metáfora da matrioshka (boneca russa que contêm dentro de si outras bonecas de diferentes tamanhos; uma boneca contém ou esconde outra(s). Em suma, a vida na rua condensa em si muitos outros fenômenos e processos sociais.

Neste número da Civitas estão reunidas contribuições sobre a vida na rua que adotam diferentes entradas, delimitações, ênfases e aproximações metodológicas. Consideramos relevante, porém, chamar a atenção para o fato de que as políticas públicas não foram abordadas de modo central por nenhum dos artigos submetidos e selecionados para o dossiê. Contudo, devemos assinalar que, apesar não terem sido abordados como objeto central, elementos importantes das políticas públicas - tais como estatísticas públicas, aspectos das políticas sociais, da política urbana e do tratamento policial às pessoas que vivem na rua - aparecem mencionados numa perspectiva sócio-histórica em resposta à questão social e às desigualdades sociais e quanto a sua efetividade em relação ao fenômeno e às situações de vida na rua. Esta aparente lacuna pode ser considerada uma abertura para construir agendas de pesquisa direcionadas especificamente para as políticas públicas, particularmente no Brasil, onde se observa poucos estudos sistemáticos sobre ações governamentais orientadas às pessoas em situação de rua.

\section{Referências}

AGIER, Michel. Managing the undesirables. Refugee camps and humanitarian government. Cambridge: Polity Press, 2010. 
BOURGOIS, Philippe. En busca de respeto: vendiendo crack en Harlem. 2. ed. Buenos Aires: Siglo XXI editores, 2015.

CHOPPIN, Katia; GARDELLA, Édouard (dir.). Les sciences sociales et le sansabrisme: recension bibliographique de langue française 1987-2012. Saint-Étienne: Publication de l'Université de Saint-Étienne, 2013.

FILGUEIRAS, Cristina A. C.; PICHON, Pascale. Percursos de vida e de pesquisa na cidade. Entrevista com Pascale Pichon. e-metropolis, revista eletrônica de estudos urbanos e regionais, n. 29, p. 50-62, 2017. <emetropolis.net/artigo/222?name= percursos-de-vida-e-de-pesquisa-na-cidade> (20 dez. 2018).

FRANGELLA, Simone M. Corpos urbanos errantes. Uma etnografia da corporalidade de moradores de rua em São Paulo. São Paulo: Annablume/Fapesp, 2010.

LEVINSON, David (dir.). Encyclopedia of homelessness, Thousand Oaks: Sage, 2004.

PICHON, Pascale. Les SDF: sortir de la rue. Discontinuités biographiques et travail de la reconversion, Paris: PUCA, 2005.

PICHON, Pascale. Vivre dans la rue. Sociologie des sans domicile fixe. Saint-Étienne: PUSE, 2007.

PICHON, Pascale; TORCHE, Thierry. S'en sortir. Accompagnement sociologique à l'autobiographie d'un ancien sans domicile fixe. Saint-Étienne: Publications de l'Université de Saint-Étienne, 2007.

PICHON, Pascale; GIROLA, Claudia; JOUVE, Élodie (dir.). Au temps du sansabrisme. Enquêtes de terrain et problème public. Saint-Étienne: Publications de l'Université de Saint-Étienne, 2016.

RUI, Taniele, MARTINEZ, Mariana; FELTRAN, Gabriel (orgs.). Novas faces da vida nas ruas. São Carlos: Eduscar, 2016.

SNOW, David. Desafortunados: um estudo sobre o povo da rua. Petrópolis: Vozes, 1998.

Recebido: 27 dez. 2018

Aceito: 27 dez. 2018

Publicado: 01 mar. 2019

CRISTINA ALMEIDA CUNHA FILGUEIRAS < cfilgueiras@pucminas.br>

Doutora em Sociologia pela École des Hautes Études en Sciences Sociales (EHESS, França). Professora e pesquisadora do Programa de Pós-graduação em Ciências Sociais da Pontifícia Universidade Católica de Minas Gerais (Belo Horizonte, MG, Brasil).

Orcid: https://orcid.org/0000-0001-6200-9770

REGINA DE PAUla MEDEIROS < repameca@pucminas.br>

Doutora em Antropologia Social pela Universitat Rovira i Virgili (Tarragona, Espanha). Professora e pesquisadora do Programa de Pós-graduação em Ciências Sociais da Pontifícia Universidade Católica de Minas Gerais (Belo Horizonte, MG, Brasil).

Orcid: https://orcid.org/0000-0002-2389-2000

PASCALE PICHON < pascale.pichon@univ-st-etienne.fr>

Doutora em Sociologia pela Université Lyon II. Professora de Sociologia na Université de Lyon/Jean Monnet (SaintÉtienne, França); pesquisadora sênior e coordenadora da equipe "Culturas políticas" do Centre Max Weber.

Orcid: https://orcid.org/0000-0002-1074-3479

GABRIEL URIBELARREA <gabriel.uribelarrea@gmail.com>

Doutorando em Sociologia na Université Lumière Lyon II. Pesquisador do Centre Max Weber na Université de LyonJean Monnet (Saint-Étienne, França).

Orcid: https://orcid.org/0000-0001-6719-6181 